\title{
Low-Frequency Vibration Effects on Coarse Particle Filtration ${ }^{\dagger}$
}

\author{
R.J. Wakeman and P. Wu \\ Advanced Separation Technologies Group, \\ Department of Chemical Engineering \\ Loughborough University*
}

\begin{abstract}
Results from an experimental investigation of the devel opment of cake resistance during filtration assisted by vibration are presented and the vibration conditions that lead to improved filtration rates are identified. It is shown that vibration is a possible technique to increase the rate of filtration. H owever, a critical acceleration that is dependent on the vibration frequency and solids mass in the cake must be exceeded for filtration to be enhanced, otherwise the rate of filtration is slowed. Changes in the visual structure of the "cake" with vibration acceleration are described and related to changes in the "cake" resistance.
\end{abstract}

\section{INTRODUCTION}

In filtration, vibration has been considered to be a method to increase the rate of filtration. RonningenPetter Div. ${ }^{1}$ introduced vibration as a means to produce slurry agitation to cut premature blinding of the filter medium, and Russel Finex ${ }^{2}$ use vibration in their sieves and filters to prevent blinding of the separator medium. Sawyer ${ }^{3}$ suggested the use of vibration to break up the cake deposited on the filter medium, and Snowball ${ }^{4}$ has more recently patented a vibratory filtration technique. Notwithstanding these applications, there has been very little published work that set out to investigate how vibration affects the filtration process. The motion of particles settling towards a vibrating filter medium has been analysed by Wakeman et $a{ }^{5}$. It was shown that the vibration of the filter medium directly affects the motion of the particles in the suspension as they approach the medium, and that critical vibration conditions exist when the particle makes infrequent contact with the medium, leaving a liquid layer above the medium and hence a higher liquid flow rate through it.

In order to investigate the effect of vibration on the filtration velocity, Bakker et al ${ }^{6}$ studied the influence of vibrations on the resistance of a polystyrene filter cake. They found that vibrations caused an increase of the cake resistance, which seems contradictory

\footnotetext{
* Loughborough, LE 11 3TU, UK.
}

† Accepted: J une 13, 2002 with the known practical applications in filtration. This suggests that if vibration is not applied properly it may reduce the filtration rate rather than improve it. Podkovyrin et $\mathrm{al}^{7}$ found that the use of vibration of the filter medium improves the filtration rate with an increase of the vibration amplitude, and Mellowes $^{8}$ developed a filtration model for candle-type filters. Further work on applications of vibration to separation problems has been reported by M etodiev et al ${ }^{9}$.

To start to understand the effects of vibration on filtration rates, vibration filtration and permeation experiments were carried out under different vibration conditions. The experimental data were processed and analysed to determine the effects of vibration on the filtration of coarse particles. This paper reports the results from these experiments.

\section{EXPERIMENTAL TECHNIQUES}

The apparatus used for the measurements is shown in Figure 1. The suspension to be filtered was prepared and stored in vessel $A$. The suspension was pumped into the filter $B$. The overflow on filter vessel $B$ ensured that the height of the suspension (and hence also the static pressure) remained constant during an experiment. The filter consisted of a filter medium ( with an area of $0.002 \mathrm{~m}^{2}$ ) attached to a rigid support. The vibration was applied to the rigid support by a vibration generator (M odel V 406) driven by a vibration control system (Model DVC 48) and a power amplifier (M odel PA500L), all supplied by Ling 


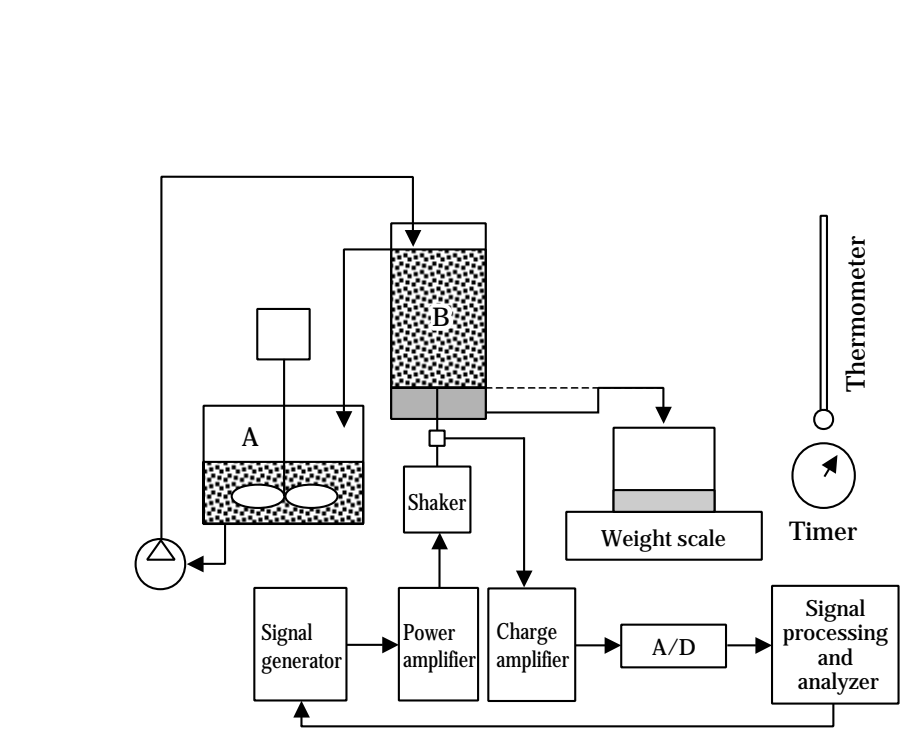

Fig. 1 Vibration filtration experimental system.

Dynamic Systems. The accelerometer (Endevco M odel 7201-560) located between the filter medium and the shaker measured the vibration acceleration of the filter medium and provided the control signal to ensure that the shaker outputted a constant acceleration during vibration. The weighing scales and the timer measured the cumulative mass of filtrate and the filtration time.

In order to investigate the effect of vibration on filtration, three groups of experiments were carried out. The first was to investigate the effect of vibration on the flow rate of liquid through the filter medium. The second set of experiments investigated the effect of vibration on the cake formation process and on the resistance of the cake during its development. The third set of experiments investigated the effects of vibration on permeation after a cake had been formed, to elucidate the relationship between cake resistance and the dynamic characteristics of the filtration system. In each experiment, vibration with a fixed frequency and acceleration was exerted on the filter medium.

A primary purpose of this initial investigation was to establish that a vibratory force could assist filtration, before further investigations were carried out to establish the mechanisms and interacting parameters between feed properties and operating parameters. In order to do this, PVC particles with the same size distribution were used in both filtration and permeation experiments. The average diameter of the particles was $126 \mu \mathrm{m}$ and the size range (measured using a M alvern M asterSizer) was 108 to $153 \mu \mathrm{m}$ (105 to 125 $\mu \mathrm{m}$ by sieving).

\section{EXPERIMENTAL RESULTS}

To measure the resistance of the filter medium, clean liquid was pumped into the filter vessel. After the vessel began to overflow, the cumulative mass of permeate and the time were measured to give the liquid flow rate. This procedure was repeated using different vibration characteristics. Some typical results are shown in Figure 2. These show the linearity between the permeate volume collected and the collection time (the offset is a result of some liquid being in the permeate receiver at the start of the test). Changes in the gradients of the lines through the data points are very small, indicating correspondingly small variations in the medium resistance at different vibration frequencies.

In the cake filtration experiments, vibration was applied to the filter medium throughout. The PVC suspension, with a concentration of $6.1 \mathrm{~kg} \mathrm{~m}^{-3}$, was fed into the filter. When the suspension began to overflow the filter vessel, the cumulative mass of filtrate and the corresponding filtration time were measured. The experiment was repeated under different conditions of vibration frequency and acceleration to give a series of filtration curves. Figure $\mathbf{3}$ shows a typical set of filtration curves measured at different vibration accelerations when the vibration frequency was 500 $\mathrm{Hz}$. The best achievable filtration rate is given by the line measured when there is no vibration and no particles in the feed, that is, water is permeating through the filter medium. Adding particles into the feed reduces the filtration rate, and low accelerations further reduce the filtration rate. Increasing the acceleration leads to higher filtration rates, and at an acceleration of $294 \mathrm{~m} \mathrm{~s}^{-2}$, the filtration rate is almost

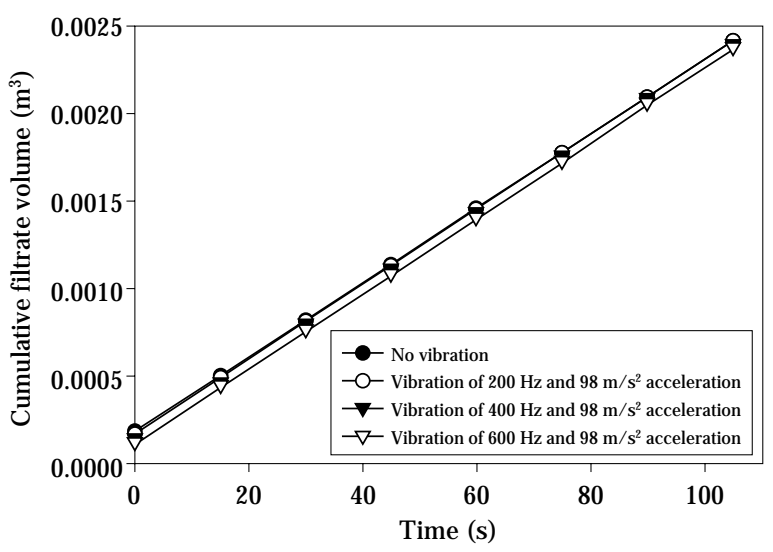

Fig. 2 The filtrate volume collected when passing a clean liquid through the filter medium. 


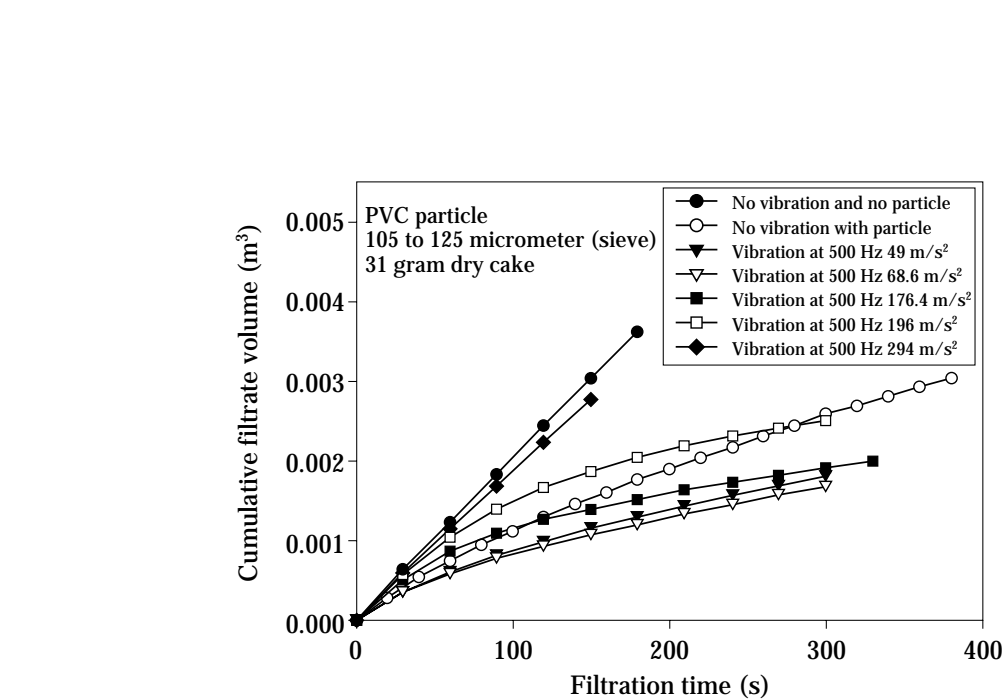

Fig. 3 The filtrate volume collected with $500 \mathrm{~Hz}$ vibration applied to the filter medium during cake filtration experiments.

as great as when only water was permeating through the filter medium, which is a substantial increase over the rate of filtration when no vibration is used.

In the cake permeation experiments, clean liquid was passed through the filter cake after it had formed. After the filter vessel started to overflow, the permeation flow rate was measured. Then vibration was applied to the filter medium. After about $30 \mathrm{~min}$ utes vibration, the flow of particles in the filter vessel approached a quasi-steady state and the permeation flow rate was measured. Figure $\mathbf{4}$ shows a typical permeation flow rate curve under different conditions of vibration acceleration. From this it is seen that acceleration had little effect on the permeate flow rate until a threshold value was reached, when the flow rate was increased substantially. There is an accelera-

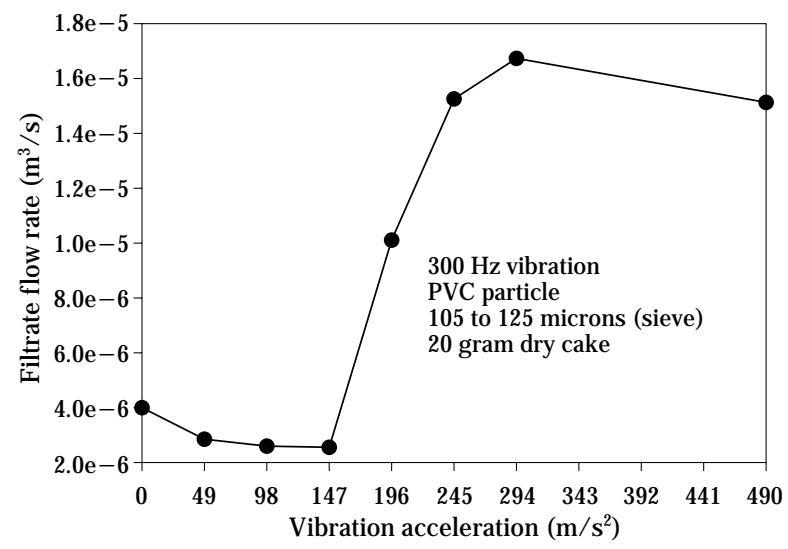

Fig. 4 Filtrate permeation rate under conditions of different vibration acceleration during cake filtration experiments. tion at which a peak flow rate is reached, and beyond that the flow decreases gradually.

\section{DISCUSSION}

A method to analyse the data and enable comparisons to be drawn is outlined below, based on the form of Darcy's law that is usually used in filtration analysis. Observations made during the experiments are then described and the data is discussed with reference to these observations and the analysis of the data.

\section{Vibration filtration theory}

In the analysis of constant pressure cake filtration, the data is conventionally plotted as $t / \mathrm{V}$ versus $\mathrm{V}$ and the straight line relation is used to estimate the average specific resistance of the cake and the medium resistance, in which $t$ is the filtration time and $\mathrm{V}$ is the cumulative filtrate volume (Wakeman and Tarleton $\left.{ }^{10}\right)$. The filtration experiments using vibration show that it is very different from cake filtration. At a fixed vibration frequency, when the acceleration is below a particular value, the straight line relation between $t / V$ and $V$ exists. Otherwise, the relation breaks down as shown in Figure 5. This means that the cake filtration theory cannot be used directly for the analysis of vibration filtration data.

During the vibration filtration process, the vibration affects the movement of particles above the filter medium and may change the flowing state of the liquid as it passes through the filter medium, when compared with filtration without vibration. This suggests
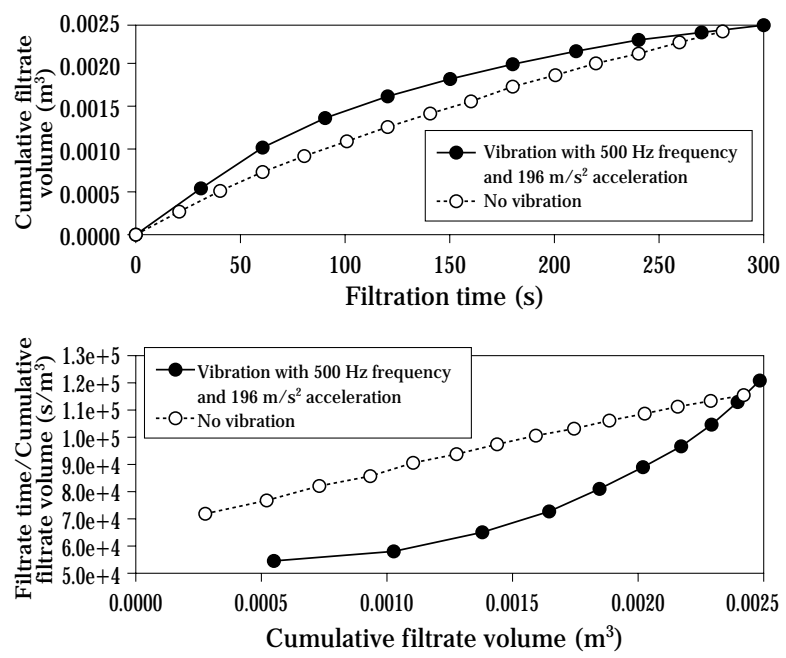

Fig. 5 Filtrate volume collected and the corresponding filtration curve obtained during a vibration filtration experiment. 
that thereseds to be an additional resistance term in the carventional filtration equation. As a preliminary approach, it is assumed that the resistance can be broken down into the following terms:

Resistance to liquid flow caused by the medium:

$$
\mathrm{R}_{\mathrm{m}} \text { (constant) }
$$

Resistance to unidirectional liquid flow through the cake:

Resistance to liquid flow arising from vibration of the medium and cake:

$R_{v}$

According to Darcy's law, the relation between the filtrate flow rate $\mathrm{Q}$ and the resistances can be written as:

$$
\mathrm{Q}=\frac{\mathrm{dV}}{\mathrm{dt}}=\frac{\mathrm{A} \Delta \mathrm{p}}{\mu\left(\mathrm{R}_{\mathrm{m}}+\mathrm{R}_{\mathrm{c}}+\mathrm{R}_{\mathrm{v}}\right)}
$$

where $\mu$ is the viscosity of the filtrate, $\mathrm{A}$ is the area of the filter medium, $\Delta \mathrm{p}$ is the filtration pressure, $\mathrm{V}$ is the cumulative volume of filtrate and $t$ is the filtration time.

The resistance $R_{v}$ can be separated into two parts. One part, $R_{v f}$ is caused by the change of the flowing state of liquid passing through the filter medium due to the vibration. The other part, $R_{v p}$, is caused by the change of particle movement in the filter vessel immediately above the filter medium, which is defined as the vibrating particle movement resistance. When no particles are in the liquid, $R_{v p}=R_{c}=0$. Under these circumstances, the resistance $R=R_{m}+R_{v f}$ is defined as the vibrating medium resistance. When the vibration is zero, $R_{v}=0$, and the equation represents normal cake filtration.

It is difficult to estimate the $R_{c}$ and $R_{v}$ individually. Here it is investigated how the vibration affects $R_{c v}=R_{c}+R_{v}$, defined as the combined cake resistance. $R_{c v}$ can be obtained from equation (1) as:

$$
\mathrm{R}_{\mathrm{cV}}=\frac{\mathrm{A} \Delta \mathrm{p}}{\mu \mathrm{Q}}-\mathrm{R}_{\mathrm{m}}=\left(\frac{\mathrm{A} \Delta \mathrm{p}}{\mu} \mid \frac{\mathrm{dV}}{\mathrm{dt}}\right)-\mathrm{R}_{\mathrm{m}}
$$

$R_{m}$ can be estimated from the experimental permeation data obtained without vibration and when only liquid was being fed to the filter. If the filtrate flow rate $Q$ at time $t$ is known, the relationship of $R_{c v}$ with filtration time $t$ can be obtained if the pressure difference $\Delta p$ across the filter is assumed to be constant during the vibration filtration process.

For the normal cake filtration, the resistance of the cake is directly proportional to the mass of dry solids deposited per unit area of filter $w$, and the proportionality constant $\alpha$ is defined as the specific cake resis- tance ( Wakeman and Tarleton ${ }^{10}$ ). For the vibration filtration, like normal cake filtration, the combined cake resistance is related to the mass of dry solids deposited per unit area of filter $w$. But the ratio between the combined cake resistance and the mass of dry solids deposited per unit area of filter is not a constant during the vibration filtration process, which changes with the filtration time. It is defined as the vibrating specific cake resistance $\alpha_{\mathrm{v}}(\mathrm{t})$. During vibration-assisted filtration, suppose that the concentration, $c$, of the feed suspension is a constant and ignore the liquid in the cake. The combined cake resistance has the relation with the vibrating specific cake resistance and the cumulative filtrate as in equation (3) ( Wakeman and Tarleton ${ }^{6}$ ):

$$
\mathrm{R}_{\mathrm{CV}}=\frac{\mathrm{CV}}{\mathrm{A}} \alpha_{\mathrm{v}}(\mathrm{t})
$$

Therefore, the average vibrating specific cake resistance, $\alpha_{\mathrm{avv}}$, can be obtained during the filtration time $\mathrm{T}$ as in equation (4):

$$
\alpha_{\mathrm{avv}}=\frac{\mathrm{A}}{\mathrm{Tc}} \int_{0}^{\mathrm{T}} \frac{\mathrm{R}_{\mathrm{cv}}}{\mathrm{V}} \mathrm{dt}
$$

where $R_{c v}$ and $V$ were related to the vibration frequency and acceleration and the filtration time. Therefore, $\alpha_{\text {avv }}$ is a function of the vibration characteristic (intensity) and the filtration time. When no vibration is exerted on the filter medium, $\alpha_{\text {avv }}$ is equal to the average specific cake resistance in conventional cake filtration.

\section{Vibration effects on medium resistance}

The vibrating medium resistance was estimated using the experimental data obtained from the medium resistance measurements, using equation (1). Some results are shown in Figures 6 and $\mathbf{7}$. When no vibration exists, $R_{\mathrm{vf}}=0$ and the medium resistance is equal to that found for a normal filtration process.

Figures $\mathbf{6}$ and $\mathbf{7}$ show that vibration changes to only a small extent the flowing state of liquid passing through the filter medium, indicated by the vibrating medium resistance being different from the medium resistance (the medium resistance is the value at zero frequency and zero vibration acceleration). The change $\left(R-R_{m}\right)$ is very small compared with $R_{m}$. In further analyses of the data, $R_{v f}$ is neglected and considered to be zero in vibration filtration.

\section{Vibration effects on cake formation}

The cake formation process (slurry thickening above the filter medium is included in this context) 


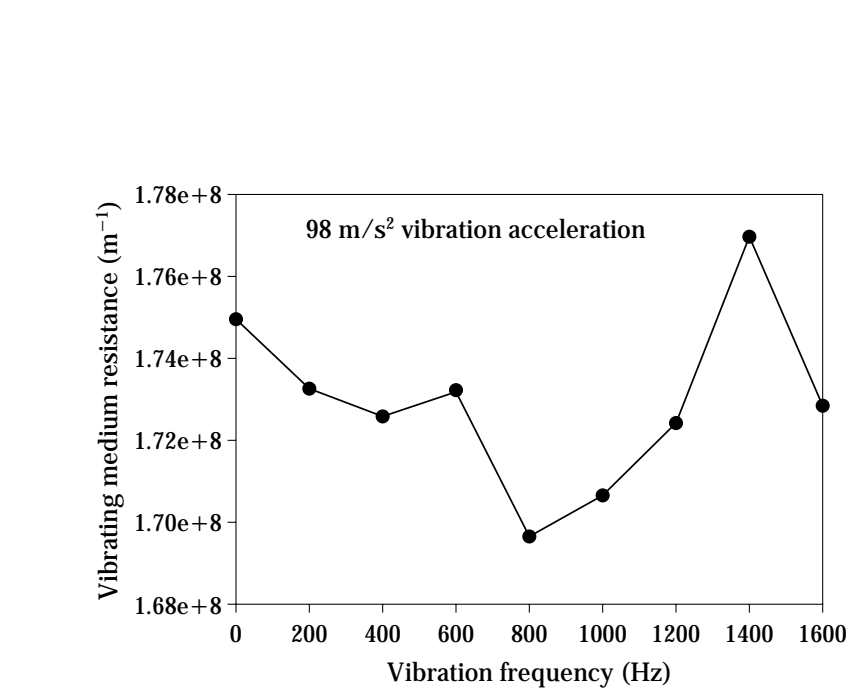

Fig. 6 The variation of the medium resistance with vibration frequency with clean liquid flowing through the medium (no filtration).

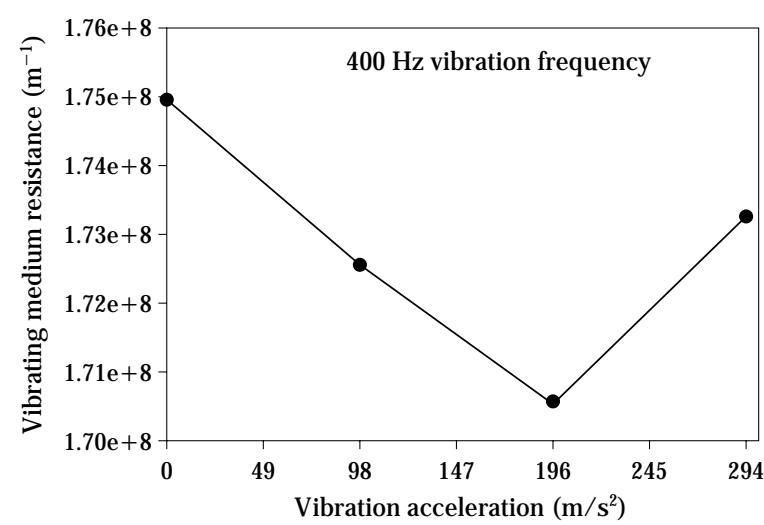

Fig. 7 The variation of the medium resistance with vibration acceleration with clean liquid flowing through the medium (no filtration).

depends on the vibration characteristics. Different vibration accelerations lead to different cake formation processes. The qualitative state of the cake or suspension in the filter chamber was observed visually through the perspex walls of the filter. When the vibration acceleration was low at a particular frequency, for example $49 \mathrm{~m} \mathrm{~s}^{-2}$ at $200 \mathrm{~Hz}$, the cake formation process was similar to that without vibration; the particles progressed in a uniform direction through the filter vessel in an orderly manner to form the cake, as shown in Figure $\mathbf{8}(\mathbf{b})$. The cake formation process changed with an increase of the vibration acceleration. At the beginning of filtration, the state of the particles was as shown in Figure 8(a), that is, the particles were uniformly distributed above the filter medium. Once the filtration had started, cake formed on the filter medium but the morphology of the cake was dependent on the vibration acceleration. For
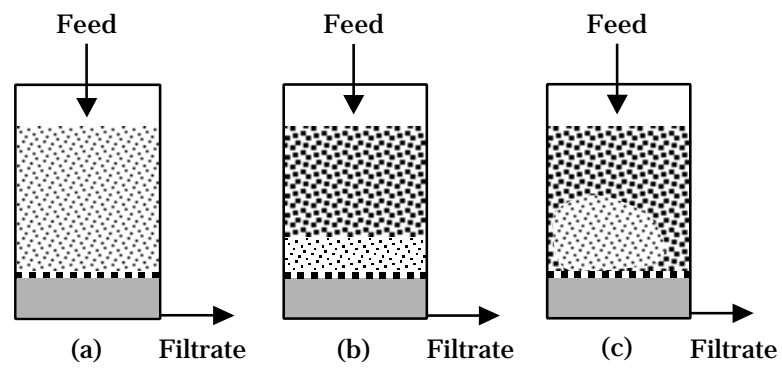

Fig. 8 State of the cake and particles during vibration-assisted filtration: the effect of increasing acceleration.

lower vibration accelerations, the shape of cake was as shown in Figure $\mathbf{8}(\mathbf{b})$, whilst at higher vibration accelerations, the form of the cake was as shown in Figure 8(c). The "cake" in Figure 8(c) does not cover the filter medium, but exists as a dense "cloud" of particles lying just above the medium. There are zones around the "cloud" through which liquid is able to flow freely and which appear to have particle concentrations similar to the feed suspension. At $500 \mathrm{~Hz}$, for example, the formation characteristics of the cake changed from that depicted in Figure 8(b) at $196 \mathrm{~m}$ $\mathrm{s}^{-2}$ to that shown in Figure 8 (c) at $294 \mathrm{~m} \mathrm{~s}^{-2}$.

\section{Combined cake resistance $\left(R_{c v}\right)$ during filtration}

After filtration a typical thickness of cake was 27 $\mathrm{mm}$. The pressure exerted on the cake was about $1638 \mathrm{~Pa}$ for a suspension with a depth of $196 \mathrm{~mm}$ in the filter vessel, and the pressure change on the cake from the beginning to the end of the filtration was about $262 \mathrm{~Pa}$. Therefore, the pressure difference exerted on the cake was assumed to be constant in the following analysis, and a value of $1800 \mathrm{~Pa}$ was used.

The combined cake resistance was estimated using the data obtained in the filtration experiments, and is shown in Figures $\mathbf{9 ,} \mathbf{1 0}$ and $\mathbf{1 1}$. These figures show that the vibration characteristics strongly affect the filtration velocity because the combined cake resistance approaches zero when the vibration acceleration exceeds a particular value, which we define as the critical vibration acceleration (CVA). The CVA depends on the vibration frequency. For example, at $200 \mathrm{~Hz}$, an acceleration greater than $98 \mathrm{~m} \mathrm{~s}^{-2}$ caused the combined cake resistance to reduce to zero (Figure 9), whereas an acceleration of $294 \mathrm{~m} \mathrm{~s}^{-2}$ at 300 and $500 \mathrm{~Hz}$ was required to produce a similar effect (Figures $\mathbf{1 0}$ and $\mathbf{1 1}$, respectively).

The rate of increase of the combined cake resistance depends on the vibration acceleration exerted on the filter medium during the filtration process. 


\section{$200 \mathrm{~Hz}$ vibration frequency}

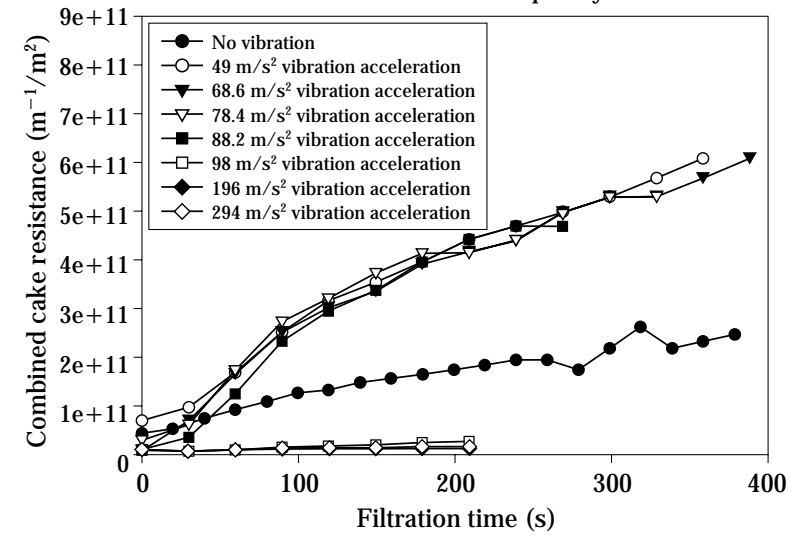

Fig. 9 Variation of the combined cake resistance with time during the vibration-assisted filtration process with the medium vibrating at $200 \mathrm{~Hz}$.

$300 \mathrm{~Hz}$ vibration frequency

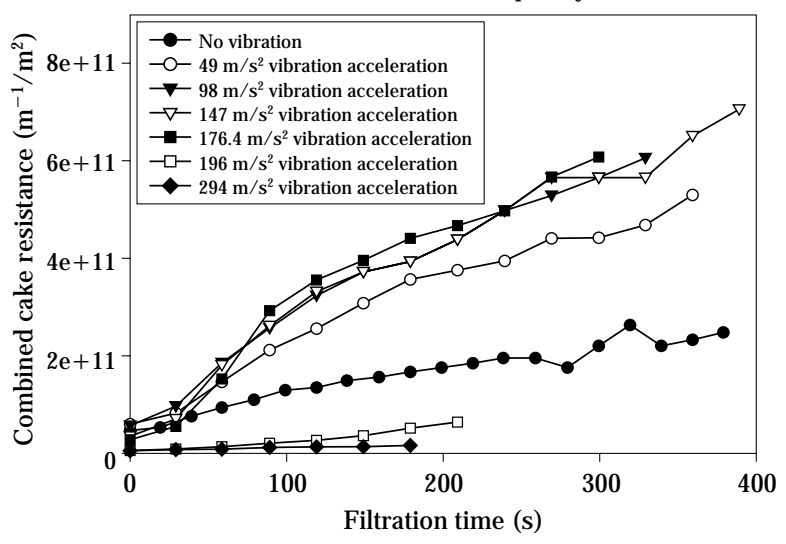

Fig. 10 Variation of the combined cake resistance with time during the vibration-assisted filtration process with the medium vibrating at $300 \mathrm{~Hz}$.

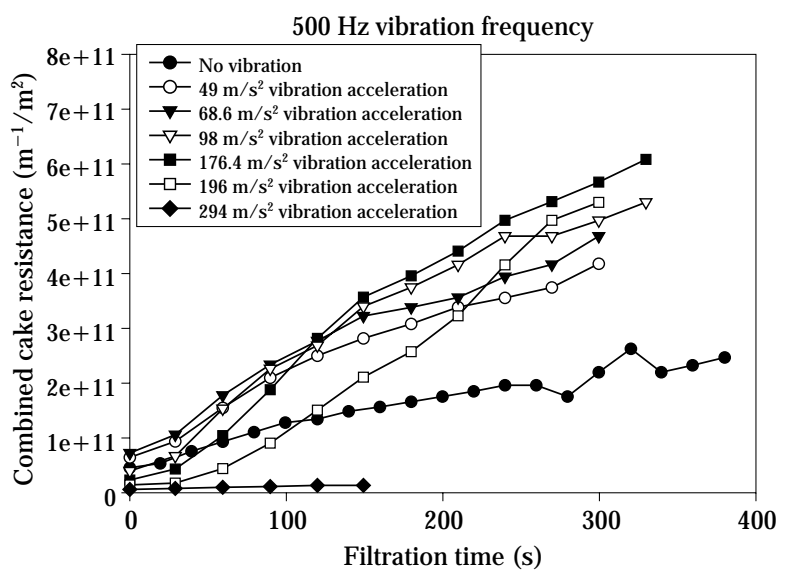

Fig. 11 Variation of the combined cake resistance with time during the vibration-assisted filtration process with the medium vibrating at $500 \mathrm{~Hz}$.
Figures 9, 10, and $\mathbf{1 1}$ show that from the start of the filtration a weak vibration acceleration, for example, $49 \mathrm{~m} \mathrm{~s}^{-2}$ at $200 \mathrm{~Hz}$ and $98 \mathrm{~m} \mathrm{~s}^{-2}$ at $300 \mathrm{~Hz}$, increases the combined cake resistance as compared with filtration without vibration. A stronger vibration acceleration decreases the resistance at the beginning of filtration, but as the filtration proceeds, all vibrations below the CVA allow the combined cake resistance to increase quickly compared with the filtration without vibration. F or example, use of $88.2 \mathrm{~m} \mathrm{~s}^{-2}$ at $200 \mathrm{~Hz}$ or $196 \mathrm{~m} \mathrm{~s}^{-2}$ at $500 \mathrm{~Hz}$ leads to a resistance during the earlier stages of filtration that is lower than is the case without vibration, but the resistance later increases sharply to become greater. Higher accelerations delay the time before the resistance starts to increase quickly, as is shown in Figure $\mathbf{1 1}$ by comparison of the curves for accelerations of 176.4 and $196 \mathrm{~m} \mathrm{~s}^{-2}$ at $500 \mathrm{~Hz}$. When the vibration acceleration is greater than the CVA, the resistance remains lower than is the case in a normal filtration. There is some evidence that the CVA may depend on the weight of cake deposited on the filter medium; for example, the 196 $\mathrm{m} \mathrm{s}^{-2}$ at $300 \mathrm{~Hz}$ curve lies below that measured for a normal filtration but after some time starts to rise towards it.

\section{Average vibration specific cake resistance $\left(\alpha_{\mathrm{avv}}\right)$ during filtration}

The average vibrating specific cake resistance changes with the vibration characteristic. The average vibrating specific cake resistance was estimated for vibration-assisted filtration at a filtration time of 150 seconds, using the experimental data and equation (4). The results are shown in Figure 12. The resistance increases at low vibration accelerations and reaches a peak value at a specific vibration acceleration dependent on the vibration frequency. The peak values are reached at 49,98 and $68.6 \mathrm{~m} \mathrm{~s}^{-2}$ at 200,300 and $500 \mathrm{~Hz}$ respectively. After the peak, the average vibrating specific cake resistance reduces with the increase of the vibration acceleration. The magnitude of these peak values are expected to depend on the size and density of the particles, a factor that will be investigated in later experiments.

Beyond the acceleration corresponding to the peak resistance values, the cake resistance falls sharply at $200 \mathrm{~Hz}$ and slowly at $500 \mathrm{~Hz}$ compared with that at $300 \mathrm{~Hz}$. When the vibration acceleration at different vibration frequency exceeds a certain value, the average vibrating specific cake resistance approaches zero and remains fairly constant. In this region, the vibration-assisted filtration behaves similarly to the 


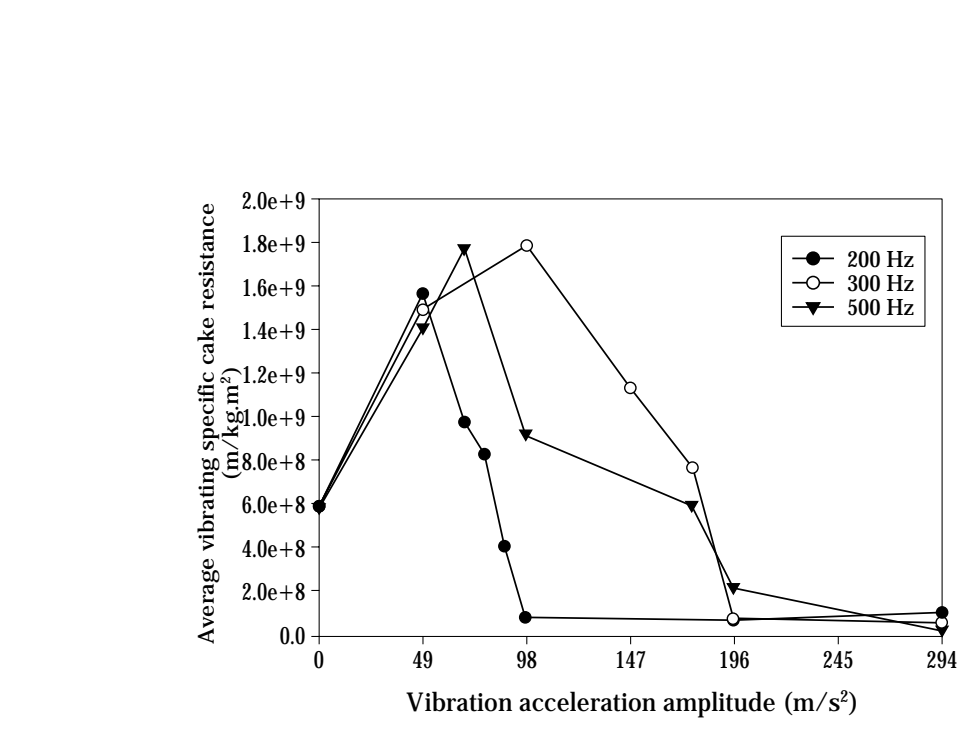

Fig. 12 Average vibrating specific cake resistance under different vibration characteristics.

permeation of a clean liquid (that is, filtration rates are similar to permeation rates through the filter medium). The filtration efficiency is then at a maximum, in the sense that a maximum filtrate flow rate is being reached even though filtration is still being achieved. The value of this vibration acceleration corresponds with the CVA.

\section{Vibration effects on permeation}

After a cake has formed, the vibration characteristics strongly affect the state of the cake. Whereas weak vibration compacted the cake, intense vibration loosened or broke up the cake and dispersed the par- ticles in the liquid. When the vibration acceleration was low at a particular frequency, for example $98 \mathrm{~m}$ $\mathrm{s}^{-2}$ at $600 \mathrm{~Hz}$, the cake compacted as shown in Figure 13(b) compared with filtration without vibration shown in Figure 13(a). There was a tendency, also, for more intense vibration to densify the cake to a greater extent. For example, the thickness of the cake after vibration at $98 \mathrm{~m} \mathrm{~s}^{-2}$ and $300 \mathrm{~Hz}$ was $15 \mathrm{~mm}$, while at $49 \mathrm{~m} \mathrm{~s}^{-2}$ and $300 \mathrm{~Hz}$ it was $16.5 \mathrm{~mm}$.

With a small increase in acceleration, the thickness of "cake" in the centre zone of the filter just above the medium increased and the thickness around the boundaries of the cake reduced, as shown in Figure 13(c) (such a result was obtained at, for example, $147 \mathrm{~m} \mathrm{~s}^{-2}$ at $300 \mathrm{~Hz}$ ). When the vibration acceleration was further increased, for example to between 196 and $274 \mathrm{~m} \mathrm{~s}^{-2}$ at $300 \mathrm{~Hz}$, a channelling phenomenon occurred and some particles in the "cake" started to flow as shown in Figure $\mathbf{1 3 ( d )}$. The change from the compaction to the channelling phenomena was gradual, caused by the increasing vibration acceleration. Increasing the vibration acceleration still further caused the particles to disperse further into the liquid just above the filter medium, as shown in Figure 13(e). At higher accelerations, for example using $490 \mathrm{~m} \mathrm{~s}^{-2}$ at $300 \mathrm{~Hz}$, the "cake" broke up completely and the particles dispersed into the liquid as shown in Figure 13(f). The acceleration at which each of the phenomena was prevalent depended on the mass of solids in the cake (in the above, the

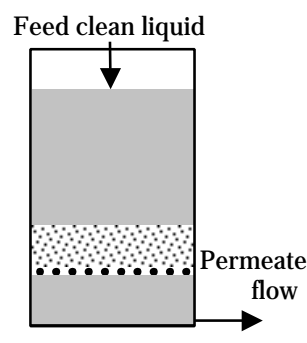

(a)

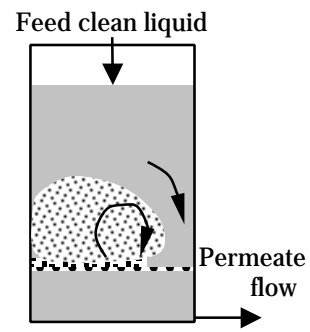

(d)

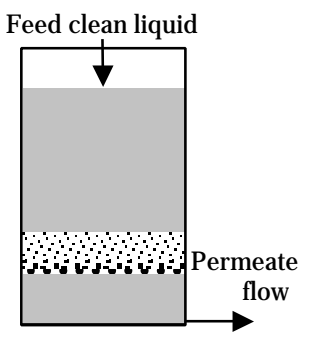

(b)

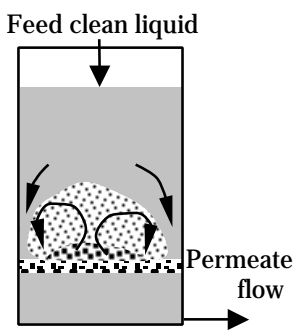

(e)

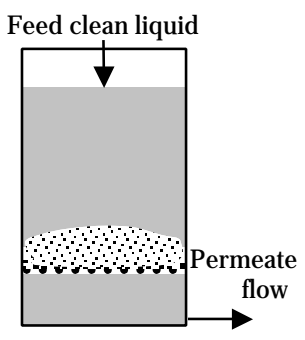

(c)

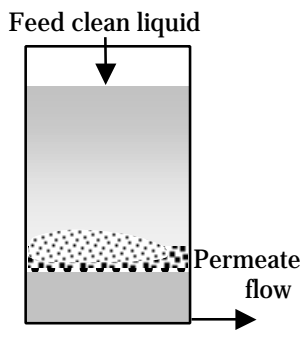

(f)

Fig. 13 State of the cake and particles during vibration permeation through a formed cake: the effect of increasing acceleration. 
masszof dry solids in the cake was 20 grams). nde $n$ ke

Combined cake resistance during permeation

The critical vibration acceleration during permeation (CVAP) depended not only on the vibration frequency but also on the mass of cake, as shown in Figure 14 obtained from the permeation experimental data. When the vibration frequency was $600 \mathrm{~Hz}$, the combined cake resistance increased with the vibration acceleration applied to a 56.77-gram dry cake. In comparison, a frequency of $200 \mathrm{~Hz}$ caused the resistance to increase with acceleration until $98 \mathrm{~m}$ $\mathrm{s}^{-2}$ was reached, beyond which the cake resistance fell to almost zero at $196 \mathrm{~m} \mathrm{~s}^{-2}$.

When the cake contained 20 grams of dry solids, vibration with $200 \mathrm{~Hz}$ and $147 \mathrm{~m} \mathrm{~s}^{-2}$ showed a similar effect (that is, the combined cake resistance approached zero). Compared with the result for the cake of 20 grams, resistances of cakes with masses of 30.06 and 56.77 grams increased to greater extents. Beyond the CVAP, the cake resistance rose again with the vibration acceleration for the 30.06- and 56.77gram cakes. The greater the mass of the cake, the bigger the increase of resistance caused by the vibration.

The combined cake resistance was related to the dynamic characteristics of the filtration system, as shown in Figure $\mathbf{1 5}$ from the permeation experimental data. For a vibration with a fixed acceleration, a higher frequency was associated with a lower vibration energy. Therefore, if the vibration acceleration was unable to break up the cake, the resistance should reduce with the increase of the vibration frequency. Figure $\mathbf{1 5}$ further shows that the resistance

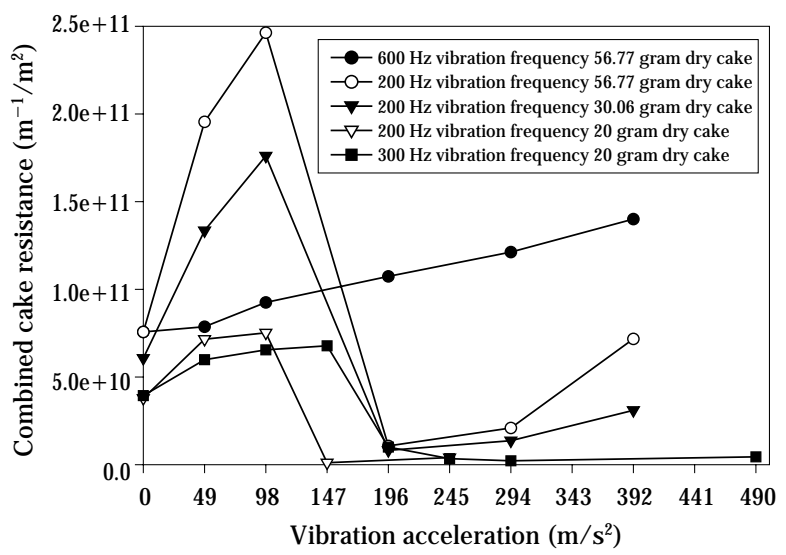

Fig. 14 Combined cake resistance for various masses of cakes under different vibration acceleration and frequency conditions during permeation experiments.

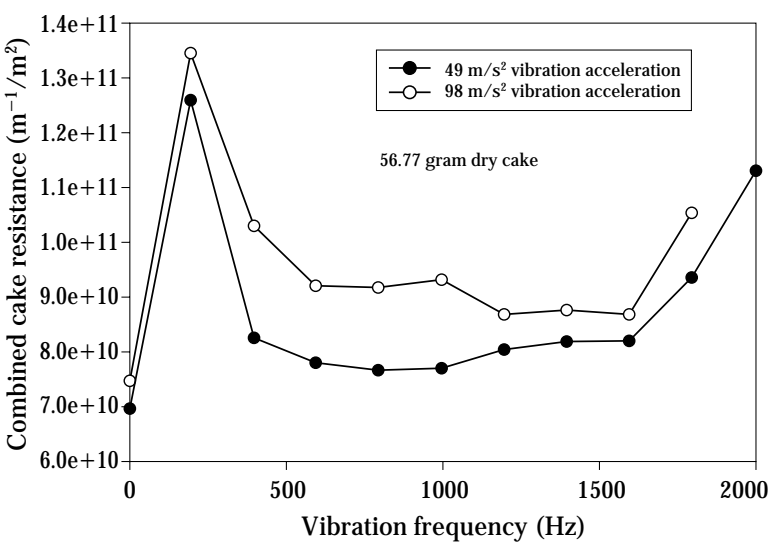

Fig. 15 Combined cake resistance under different vibration frequency and acceleration conditions during permeation experiments.

increases with an increase of the vibration frequency at frequencies above $1600 \mathrm{~Hz}$.

Comparing the filtration and permeation experimental results, the conclusion can be obtained that critical vibration accelerations for filtration and permeation are different. The critical vibration acceleration during permeation is larger than that during filtration (CVA <CVAP). For example, when a $200-\mathrm{Hz}$ vibration was applied, CVAP for a 20-gram cake was $147 \mathrm{~m} \mathrm{~s}^{-2}$ as shown in Figure 14, while CVA for a 31gram cake was $98 \mathrm{~m} \mathrm{~s}^{-2}$ as shown in Figure $\mathbf{9}$.

\section{CONCLUSIONS}

Vibration of the filter medium caused only a small change to the resistance experienced by filtrate passing through it, which itself was small compared with the resistances of the cakes formed. However, the resistance of the cake could be reduced substantially under the correct conditions of vibration.

Vibration can increase the rate of filtration, but its intensity has to be greater than the critical vibration acceleration. In turn, the critical vibration acceleration is related to the vibration frequency, the weight of dry solids in the cake and the dynamic characteristics of the filtration system. Also, the critical vibration acceleration obtained during filtration is different from that obtained during fluid permeation through an already formed cake. If the vibration acceleration is smaller than the critical vibration acceleration, the vibration cannot improve the rate of filtration but will in fact slow it. 
ENQMUÉ NCLATURE

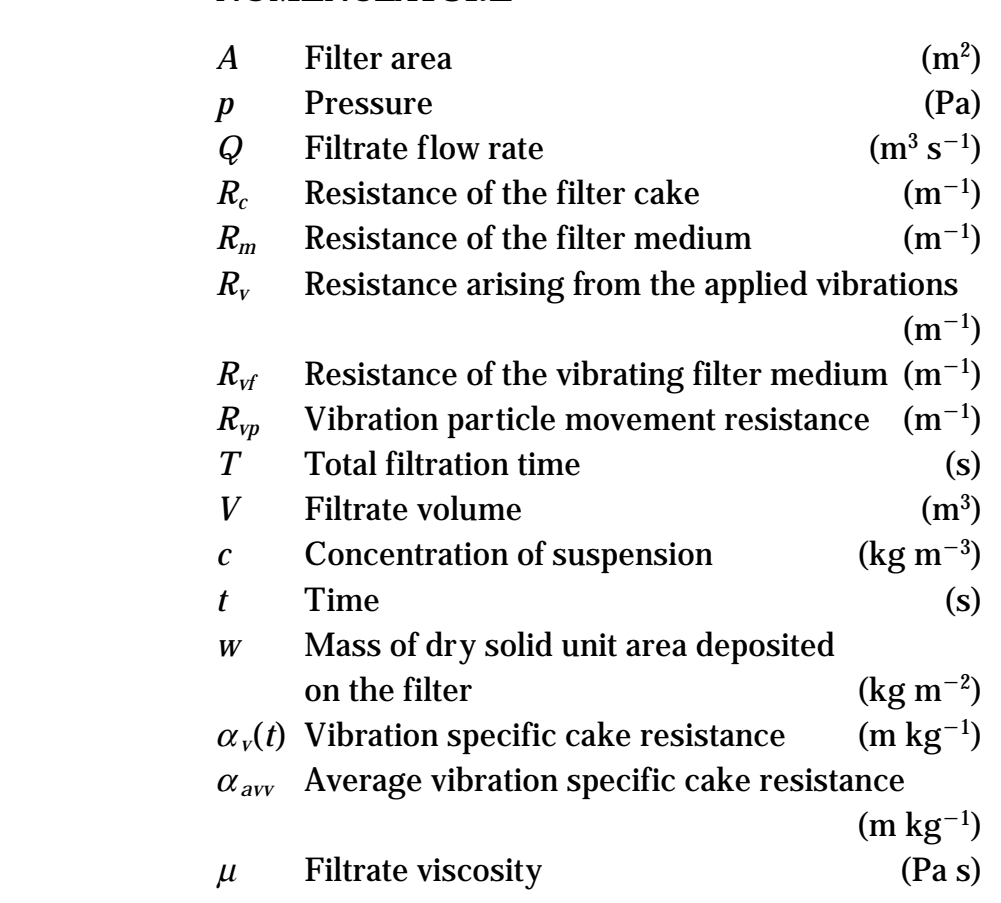

\section{ACKNOWLEDGEMENT}

The authors wish to record their gratitude for receipt of an Engineering and Physical Sciences Research Council grant in support of this work.

\section{RE FE RENCES}

1) Ronning-Petter Div., Dover Corp.: Chemical Engineering, 80(6), M arch 19, 1973.

2) Russell Finex, Company Brochures.

3) Sawyer, J.: Dynamic self-cleaning filter for liquids, US patent No. 4158629, J une 19, 1979.

4) Snowball, M .R.: Fluid treatment by filtration and vibration, European patent N o. EP1094036, A pril, 2001.

5) Wakeman R.J., Wu P. and Koenders M .A.K.: Simulation of the motion of particles settling towards a vibrating filter medium, Transactions of The Filtration Society, $\mathbf{2}$ (1), 2001, 13-19.

6) Bakker P.J., Heertjes, P.M. and Hibou, J.L.: The influence of the initial filtration velocity and of vibrations on the resistance of a polystyrene filter cake, Chemical Engineering Science, 10, 1950, 130-140.

7) Podkovyrin A.I., Korol'kov V.V. and Isakov A.P.: Filtering a fibrous suspension through a vibrating grid, Khimicheskoe I Neftyanoe Mashinostroenie, 1, 1973, 1314.

8) M ellowes, W.A.: A vibratory filtration model for candletype filters, Powder Technology, 43, 1985, 203-212.

9) M etodiev M ., Stoev S. and Hall S.T.: Vibration spiral filtration, Mining and Geology, Sofia, Bulgaria, No. 5, 1996, 28-31 (in Bulragian).

10) Wakeman R.J. and Tarleton E.S.: Filtration: Equipment selection modelling and process simulation, Elsevier, 1999. 


\section{Wuthor's short biography}

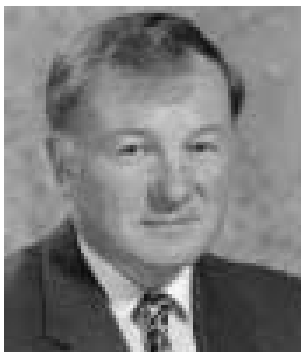

\section{Richard J. Wakeman}

Richard Wakeman is Professor and Head of the Department of Chemical Engineering at Loughborough University. He has worked extensively on most aspects of solid/ liquid separation, including pre- and post-treatment processes, membrane filtration and the development of filter media. These works now also include field assisted separation techniques - the concentration and filtration of particulates using electrical, ultrasonic or vibrating force fields. He has been the recipient of M oulton M edals from the Institution of Chemical Engineers in 1978, 1991 and 1995 and the Gold M edal of The Filtration Society in 1993. He was elected a Fellow of The Royal Academy of Engineering in 1996.

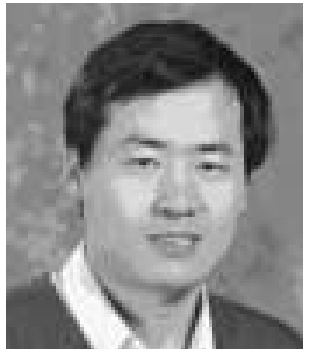

\section{Pihong Wu}

Pihong Wu was born in China in 1964. He received his Bachelor degree in Taiyuan Heavy M achine Institute in 1984, M aster degree in Shanxi M ining Institute in 1987, and $\mathrm{PhD}$ in Southampton Institute in 2001.

$\mathrm{He}$ worked as a Scientist in Mining Science and Technology Research Institute during 1987 to 1997. Currently he is a postdoctoral research associate at Loughborough University. $\mathrm{H}$ is research interests include multivariate data analysis, neural networks, fuzzy logic, digital signal processing, system modelling and simulation, and vibration analysis and control. 